\title{
BMJ Open How far is too far? A nationwide cross- sectional study for establishing optimal hospital access time for Korean pregnant women
}

\author{
Mi Young Kwak, ${ }^{1}$ Seung Mi Lee, ${ }^{2}$ Hyun Joo Kim, ${ }^{3}$ Sang Jun Eun, ${ }^{4}$ Won Mo Jang, ${ }^{5}$ \\ Hyemin Jung, ${ }^{6}$ Yoon Kim, ${ }^{6}$ Jin Yong Lee ${ }^{6,7}$
}

To cite: Kwak MY, Lee SM, Kim HJ, et al. How far is too far? A nationwide cross-sectional study for establishing optimal hospital access time for Korean pregnant women. BMJ Open 2019;9:e031882. doi:10.1136/ bmjopen-2019-031882

- Prepublication history for this paper is available online. To view these files, please visit the journal online (http://dx.doi. org/10.1136/bmjopen-2019031882).

MYK and SML contributed equally.

Received 23 May 2019 Revised 30 July 2019

Accepted 02 September 2019

Check for updates

(C) Author(s) (or their employer(s)) 2019. Re-use permitted under CC BY-NC. No commercial re-use. See rights and permissions. Published by BMJ.

For numbered affiliations see end of article.

Correspondence to

Dr Jin Yong Lee;

jylee2000@gmail.com

\section{ABSTRACT}

Objectives Access to a delivery unit is a major factor in determining maternal morbidity and mortality. However, there is little information about the optimal access time to a delivery unit. This study aimed to establish the optimal hospital access time (OHAT) for pregnant women in South Korea.

Design Nationwide cross-sectional study.

Setting We used the National Health Insurance System database of South Korea.

Participants We analysed the data of 371341 women who had experienced pregnancy in 2013.

Primary and secondary outcome measures Access time to hospital was defined as the time required to travel from the patient's home to the delivery unit. The incidence of obstetric complications was plotted against the access time to hospital. Change-point analysis was performed to identify the OHAT by determining a point wherein the incidence of obstetric complications changed significantly. As a final step, the risk of obstetric complications was compared by type among pregnant women who lived within the OHAT against those who lived outside the OHAT. Results The OHAT associated with each adverse pregnancy outcomes were as follows: inadequate prenatal care, 41-50 min; preeclampsia, 51-60 min; placental abruption, 51-60 min; preterm delivery, 31-40 min; postpartum transfusion, 31-40 min; uterine artery embolisation, 31-40 min; admission to intensive care unit, 31-40 min; and caesarean hysterectomy, 31-40 min. Pregnant women who lived outside the OHAT had significantly higher risk for obstetric complications than those who lived within the OHAT.

Conclusions Our results showed that the OHAT for each obstetric complication ranged between 31 and $60 \mathrm{~min}$. The Korean government should take the OHAT under consideration when establishing interventions for pregnant women who live outside OHAT to reduce maternal morbidity and mortality.

\section{INTRODUCTION}

Adequate access to a healthcare system is an important issue in public health. The American Institute of Medicine defined it as 'the timely use of personal health services to achieve the best possible health outcomes'
Strengths and limitations of this study

- We used large linked database representing all pregnancies in South Korea to investigate the association between geographical access time and adverse maternal outcome.

- The access time to hospital was calculated by using the road network analysis by a geographic information system with big national health data, which lends further credibility to its results.

- We confirmed that long travel time from home to hospital could affect the health of mothers and babies.

- Limitations include some essential health outcomes of neonates such as neonatal weight, congenital anomalies, or infant mortality could not be examined due to restricted access to relevant data

and classified three types of barriers for timely access: structural, financial and personal. ${ }^{1}$ Distance to healthcare services is one of the most important out of all structural barriers. For example, rural parturient women who have to travel to access maternity services have increased rates of adverse outcomes and newborns have increased numbers of Neonatal Intensive Care Unit (NICU) 2 and 3 care days in developed country. ${ }^{2}$

Although the number of counties in which more than $10 \%$ of women lived outside the 1 hour zone from obstetric institution, the geographical accessibility has gained little attention even in well-developed countries. ${ }^{3}$ Relatively few studies have reported that longer distance increases the risk of adverse pregnancy outcomes even in developed countries. ${ }^{34}$ However, the optimal access time to delivery unit that reduces adverse obstetric outcomes has not been evaluated, although it is of paramount importance in public health policy on maternal care. 
According to the amendment of the Maternal and Child Health Law, the foundation for the establishment of the Center for Maternal Maternity Care was established in 2018. Perinatal healthcare networks (regional-local maternity medical center-obstetric care underserved areas (OCUA) centre) are established. But mothers choose hospitals according to their free will and give birth everywhere. The 17 high-level local administrative territories of the South Korea shall consist of one Seoul metropolitan city, six metropolitan cities, one self-governing city and nine provinces. There are 250 low-level local governmental areas in total. In recent decades, there has been a trend of closing small-size obstetric units in South Korea. As a result, 38 regions among 250 administrative districts are designated as 'OCUA' where there are no obstetrics and gynaecology clinics or hospitals providing prenatal care and delivery services. ${ }^{5}$ This development is coincident with worldwide regionalisation of health services that has resulted in challenges to recruiting healthcare providers in rural areas. ${ }^{67}$ The government defines OCUA as regions where more than $30 \%$ of residents lack access to delivery services within a 60 min drive and where obstetric care utilisation rate is less than $30 \%$ in 60 min (Timely Relevance Index rate). However, no previous study has provided evidence that sufficiently supports the $60 \mathrm{~min}$ benchmark. In view of public health policy, identifying the optimal access time to delivery unit is a critical issue. If the optimal geographical access time is appropriately established, maternal health policy may focus on pregnant women who live outside the optimal hospital access time (OHAT) to reduce adverse pregnancy outcomes that result from structural barriers to healthcare system. For this purpose, we undertook this study to establish the OHAT in South Korea.

\section{METHODS}

\section{Data source and study design}

In this nationwide cross-sectional study, we used National Health Insurance System (NHIS) database of South Korea. NHIS is the only healthcare insurer in South Korea providing health insurance to all Koreans. It has been accumulating medical records and personal information based on medical claim data submitted from healthcare providers. For this reason, we were able to analyse all of South Korea's labour data. Using the NHIS database, we selected of 371341 pregnant women who had experienced pregnancy (including delivery and pregnancy with abortive outcome) from 1 January 2013 to 31 December 2013. Then, we connected each person's claims data and personal geographical information from NHIS database and National Spatial Data Infrastructure Portal. In order to evaluate prenatal and postpartum care, we used the data before and after event year (2012 and 2014).

\section{Definition of access time to hospital}

We extracted the information on each woman's address and location of the delivery unit where the woman's delivery took place. 'Access time to hospital' was defined as the travel time by car from the pregnant women's residence to a department of obstetrics and gynaecology where they gave birth. Travel time by car was calculated with a geographic information system (GIS) package including a national drive time matrix, which took into account the Ministry of Land, Infrastructure and Transport network analysis system. The Ministry of Land, Transport and Maritime Affairs has developed a programme (National Spatial Data Infrastructure Portal: http://www. nsdi.go.kr/lxmap/index.do) for urban development projects using GIS. This GIS programme helps to efficiently perform the national land space planning work by combining land information such as land management, construction administration and land-use regulation with GIS. In our study, we measured the distance and driving time with the national health insurance claim data using GIS developed by The Ministry of Land, Transport and Maritime Affairs.

\section{Definitions of obstetric complications}

Obstetric complications included: preeclampsia, placental abruption, preterm delivery, postpartum transfusion, uterine artery embolisation, admission to intensive care unit (ICU) and caesarean hysterectomy, all of which are known to be increased in areas with low accessibility to medical care. ${ }^{8-13}$ These obstetric complications were defined based on the International Classification of Diseases-10 and electronic data interchange code (table 1). Finally, inadequate prenatal care was defined as number of hospital visits during pregnancy of less than four times, adopted from the Kessner Index. ${ }^{14}$

\section{Definition of OHAT}

Predicted incidence rates of obstetric complications per 1000 pregnant women were calculated by multiple regression model adjusted for maternal age, socioeconomic status, Charlson Comorbidity Index, urbanisation and size of the hospital. Charlson Comorbidity Index was adopted to reflect the effect of individual health status. ${ }^{15-17}$ The predicted incidence rates per 1000 pregnant women for overall and each obstetric complication were plotted against access time to hospital at $10 \mathrm{~min}$ intervals to determine the OHAT. Change-point analysis (CPA) defined OHAT as a point where the incidence of obstetric complications significantly changed. The procedure for performing a CPA iteratively uses a combination of cumulative sum charts (CUSUM) and bootstrapping to detect the changes. A bootstrap is performed by: generate a bootstrap sample of data 10 min' units and based on the bootstrap sample, calculate the bootstrap CUSUM, denoted $10 \mathrm{~min}, 20, \ldots, 350 \mathrm{~min}$. And then calculate the maximum, minimum and difference of the bootstrap CUSUM. Then, the confidence level (CL) is required that a significant change has been detected. If there are 995 which had significant change, out of 1000 bootstraps, this gives a CL of: (confidence level $=100 * 995 / 100 \%=99.5 \%$ ). 
Table 1 The definition of abortion, delivery and obstetric complications

\begin{tabular}{ll}
\hline Variables & ICD-10 code and EDI code \\
\hline $\begin{array}{l}\text { Abortion } \\
\text { Delivery }\end{array}$ & O00-O08(O00-O089) \\
\hline $\begin{array}{l}\text { Caesarean section } \\
\text { Vaginal delivery }\end{array}$ & O82 (O820-O829), O842 (O800-O809), O81 (O810-O815), O83 (O830-O839), O840, O841 \\
\hline $\begin{array}{l}\text { Obstetric complications } \\
\text { Preeclampsia }\end{array}$ & O14 (O140-O149) \\
\hline $\begin{array}{l}\text { Eclampsia } \\
\text { Placental abruption }\end{array}$ & O15 (O150-O159) \\
\hline $\begin{array}{l}\text { Preterm delivery } \\
\text { Postpartum transfusion }\end{array}$ & O60150-O459) \\
\hline Admission to ICU & AJ110, AJ210, AJ120, AJ220, AJ130, AJ230, AJ140, AJ240, AJ150, AJ250, AJ100, AJ200, AJ300, AJ180, \\
\hline $\begin{array}{l}\text { Uterine artery } \\
\text { embolisation }\end{array}$ & AJ280, AJ380 \\
\hline Caesarean hysterectomy & R4507, R4508, R4509, R4510, R5001, R5002 \\
\hline
\end{tabular}

EDI, electronic data interchange; ICD, International Classification of Diseases; ICU, intensive care unit.

\section{Statistical analysis}

All analyses were conducted with SAS, V.10.2 (SAS Institute). All statistical tests were two sided and a $\mathrm{p}<0.05$ was considered statistically significant. In addition, we used CPA tool developed by Taylor ${ }^{18}$ to get the OHAT. CPA tool is a method that allows to determine whether a change has taken place in time series dataset; it is effective at detecting non-periodic events from data. ${ }^{20}$ Furthermore, it better characterises the changes detected by providing CLs and CIs. Finally, we used multiple logistic regression analysis to compare the risks of adverse obstetric outcomes between patients who live within the OHAT and those live outside the OHAT.

\section{RESULTS}

Data on 371341 women were included in the analysis (table 2).

Level of income was categorised as high level (upper $25 \%$ of premium), intermediate level (middle $50 \%$ ) and low level (lower 25\%) based on their national health insurance premium.

Figure 1 shows the distribution map of the number of pregnant women according to 250 municipalities. The number of deliveries was divided into five categories $(\leq 308$, 309-1305, 1306-2299, 2300-3743, >3744).

Figure 2 shows the distribution of the number of pregnant women according to access time to hospital; $84 \%$ of pregnant women resided within $60 \mathrm{~min}$ from hospital; $92 \%$ within $120 \mathrm{~min}$; $97 \%$ within $180 \mathrm{~min}$.

Figure 3 demonstrates the predicted incidence rates per 1000 pregnant women and cumulative rates of all or each obstetric complication against access time to hospital (minutes). CPA estimated the OHAT for each adverse pregnancy outcome as follows:
- 41-50 min for inadequate prenatal care,

- 51-60 min for eclampsia or preeclampsia,

- 51-60 min for placental abruption,

- 31-40 min for preterm delivery,

- 31-40 min for postpartum transfusion,

- 31-40 min for uterine artery embolisation,

- 31-40 min for admission to ICU, and

- 31-40 min for caesarean hysterectomy (figure 3 and table 3).

Table 3 represents change-point (CP) time as outcome variability (CI) with confidence level (CL) as estimated by the CPA tool. Average CP time is $46 \mathrm{~min}$ on eight outcome indicators. For example, the incident cases per 1000 mothers for inadequate prenatal care tend to occur with significant meaningful change at 41-50 min of access time to hospital (100\% CL). For each obstetric complication indicator, incident cases per 1000 mothers for preeclamsia or eclampsia $(100 \% \mathrm{CL})$ and placental abruption (99\% CL) tend to occur with significant meaningful change at 51-60 min of access time to hospital. And incident cases per 1000 mothers for preterm delivery (97\% CL), postpartum transfusion (97\% CL), uterine artery embolisation (97\% CL), admission to ICU (97\% CL) and caesarean hysterectomy (97\% CL) tend to occur with significant meaningful change at 41-50 min of access time to hospital.

In logistic regression analysis, patients who live outside OHAT had significantly higher risk for obstetric complications than those who live within OHAT after adjusting confounding variables (table 4). Pregnant women who live outside OHAT (41-50 min) have a higher risk of inadequate prenatal care (adjusted OR (aOR) 1.17, 95\% CI 1.06 to 1.28 ) than the women who live within $40 \mathrm{~min}$ of access time to hospital. Pregnant women who live outside 


\begin{tabular}{|c|c|}
\hline Variables & No $(\%)$ of women \\
\hline Total & $371341(100.0)$ \\
\hline \multicolumn{2}{|l|}{ Age } \\
\hline Mean \pm SD & $31.5 \pm 4.19$ \\
\hline \multicolumn{2}{|l|}{ Area* $^{*}$} \\
\hline Metropolitan & $238416(64.2)$ \\
\hline City & $109415(29.5)$ \\
\hline Rural & $23510(6.3)$ \\
\hline \multicolumn{2}{|l|}{ Type of insurance } \\
\hline $\mathrm{NHI}$ & 369179 (99.3) \\
\hline MA & $2162(0.7)$ \\
\hline \multicolumn{2}{|l|}{ Level of income } \\
\hline High (upper 25\%) & $64127(17.26)$ \\
\hline Medium (25\%-75\%) & $247612(66.68)$ \\
\hline Low (lower 25\%) & $59602(16.05)$ \\
\hline \multicolumn{2}{|l|}{ Termination of pregnancy } \\
\hline Abortion & $13254(3.56)$ \\
\hline Delivery & 358087 (96.43) \\
\hline \multicolumn{2}{|l|}{ Result of childbirth } \\
\hline Live birth & $356346(95.96)$ \\
\hline Stillbirth & $1741(0.46)$ \\
\hline Subtotal & 358087 (96.43) \\
\hline \multicolumn{2}{|l|}{ Type of delivery } \\
\hline Caesarean section & $125761(33.86)$ \\
\hline Vaginal delivery & 230585 (62.09) \\
\hline Subtotal & 356346 (95.96) \\
\hline
\end{tabular}

MA, Medical Aid; NHI, National Health Insurance.

OHAT (31-40 min) have higher risk of preterm delivery (OR 2.2, 95\% CI 1.96 to 2.47), uterine artery embolisation (OR 1.54, 95\% CI 1.05 to 1.83), admission to ICU (OR $1.42,95 \% \mathrm{CI} 1.02$ to 1.98 ) and caesarean hysterectomy (OR 2.69, 95\% CI 1.09 to 6.65) than the women who live within $30 \mathrm{~min}$ of access time to hospital. Pregnant women who live outside OHAT (51-60 min) have a higher risk of placental abruption (OR 3.23, 95\% CI 1.57 to 6.64 ) and

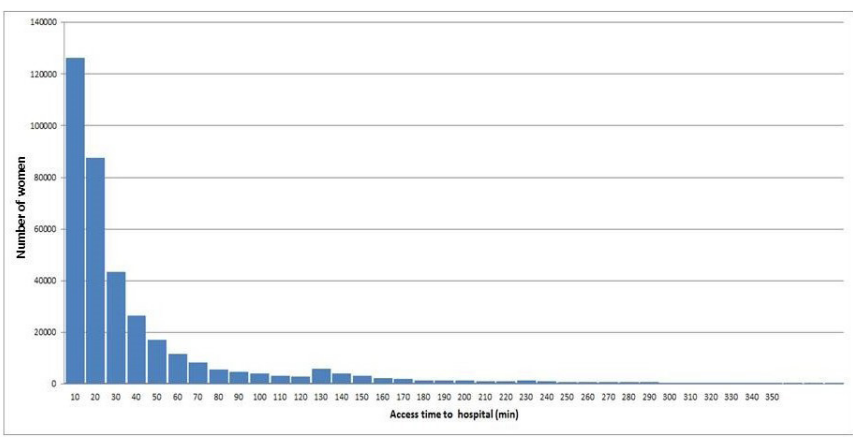

Figure 2 The number of pregnant women according to access time to hospital.

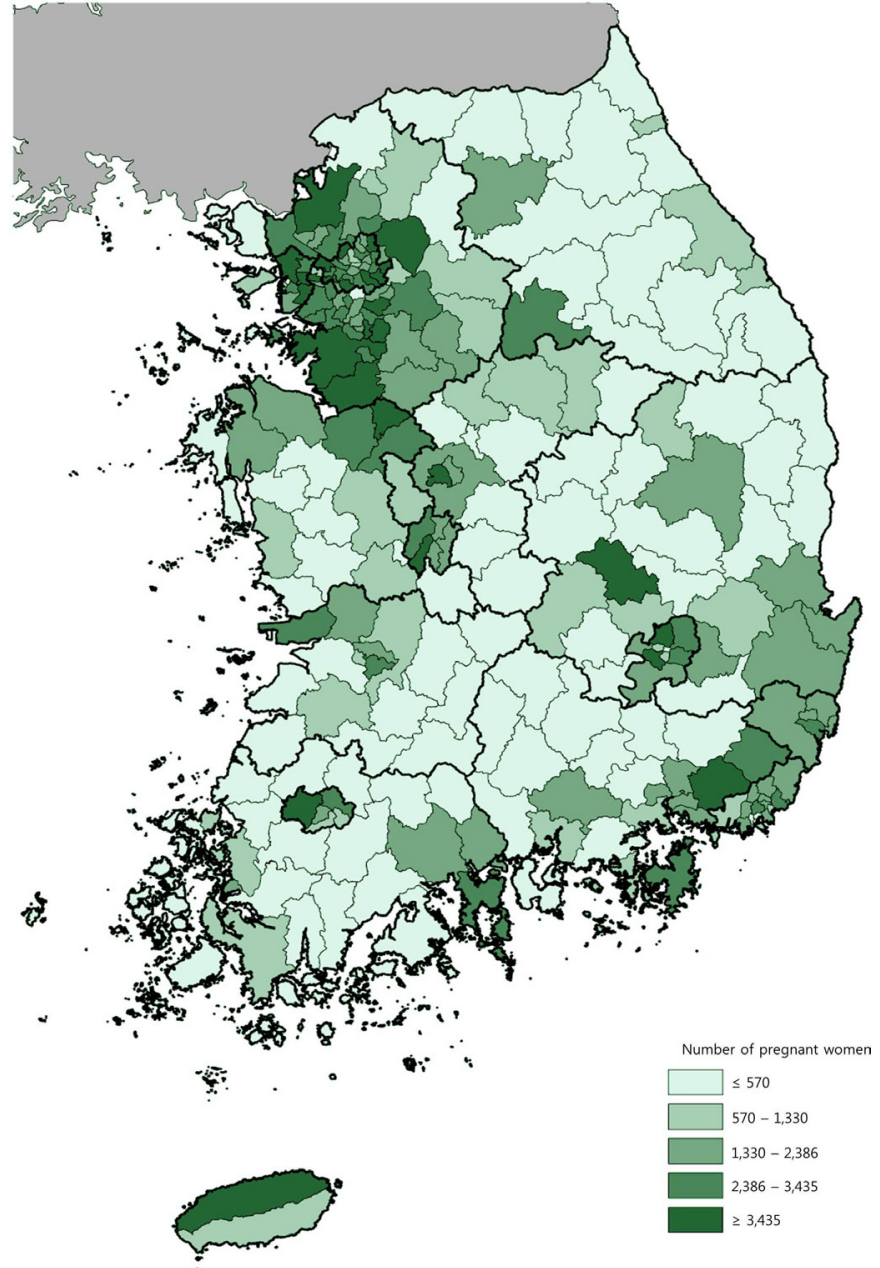

Figure 1 The number of pregnant women according to lowlevel local governmental areas.

preeclampsia or eclampsia (OR 2.03, 95\% CI 1.32 to 3.10 ) than the women who live within $50 \mathrm{~min}$ of access time to hospital.

\section{DISCUSSION}

The OHAT for each adverse pregnancy outcome was ranged 30-60 min depending on the specific adverse outcome. In addition, pregnant women who live outside OHAT had 1.17 to 3.23 times higher risk of obstetric complications than those who live within OHAT.

The current study found that the CPs of inappropriate prenatal care and obstetric complications were within $60 \mathrm{~min}$, in accordance to the result of previous studies. In addition, we also evaluated the significant CPs for each complication. The CPs of postpartum haemorrhage (transfusion, uterine artery embolisation, caesarean hysterectomy), preterm delivery and admission to ICU were 31-40 min, which was earlier than inadequate prenatal care, preeclampsia or placental abruption (41-60 min). This reflects the fact that the emergent diagnostic and therapeutic interventions are essentially needed within $60 \mathrm{~min}$ for reduction of these complications. In addition, the public resources might have to be more concentrated 
A

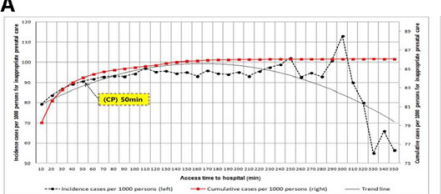

B

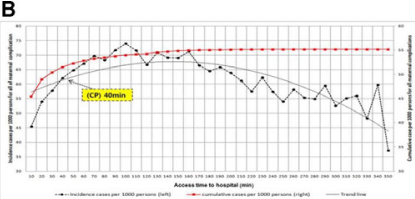

C

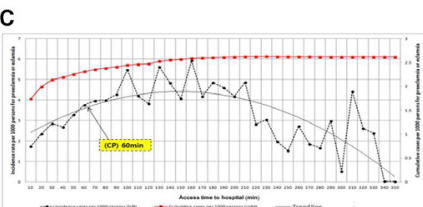

D

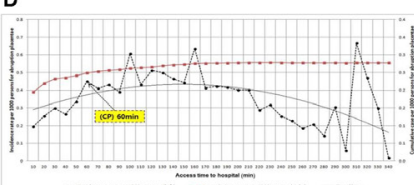

E

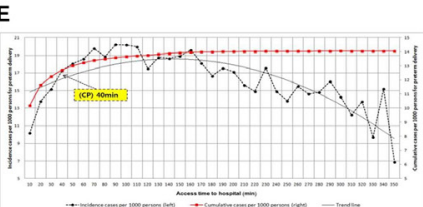

$\mathbf{F}$

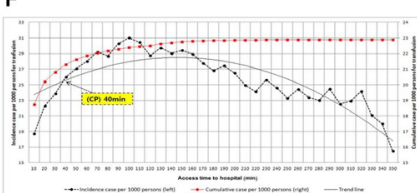

G
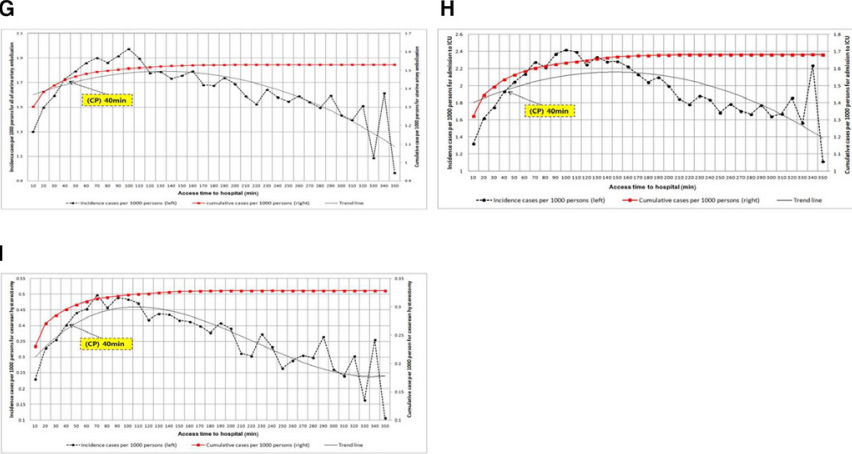

Figure 3 The predicted and cumulative incidence of obstetric complications and access time to hospital. CP, change point.

Table 3 Change points (CPs) of inappropriate prenatal care and obstetric complications

\begin{tabular}{|lll|}
\hline & \multicolumn{2}{l}{$\begin{array}{l}\text { Significant change } \\
\text { point }\end{array}$} \\
\cline { 2 - 3 } Obstetric complications & CP time (CI) & CL \\
\hline $\begin{array}{l}\text { Inadequate prenatal care (Kissner } \\
\text { Index* } \leq 4)\end{array}$ & 41 to $50 \mathrm{~min}$ & $100 \%$ \\
\hline $\begin{array}{l}\text { Overall obstetric complication } \\
\text { Preeclampsia or eclampsia }\end{array}$ & 31 to $40 \mathrm{~min}$ & $100 \%$ \\
\hline Placental abruption & 51 to $60 \mathrm{~min}$ & $100 \%$ \\
\hline Preterm delivery & 51 to $60 \mathrm{~min}$ & $99 \%$ \\
\hline Postpartum transfusion & 31 to $40 \mathrm{~min}$ & $99 \%$ \\
\hline Uterine artery embolisation & 31 to $40 \mathrm{~min}$ & $97 \%$ \\
\hline Admission to ICU & 31 to $40 \mathrm{~min}$ & $97 \%$ \\
\hline Caesarean hysterectomy & 31 to $40 \mathrm{~min}$ & $97 \%$ \\
\hline
\end{tabular}

*Kessner Index is based on the total number of visits for prenatal cares during pregnancy. If they visited less than four times, it was evaluated as 'inadequate'.

$\mathrm{CL}$, confidence level; ICU, intensive care unit. to reduce these acute complications in women who reside far from hospitals.

This study also aimed to show an association between geographical accessibility and maternal outcomes in South Korea to establish and validate OHAT for OCUA. Pregnant women who lived outside the OHAT had significantly higher risk for obstetric complications than those who lived within the OHAT (aOR 1.17-3.23; 95\% CI 1.02 to 6.65$)$.

Long travel time from home to hospital could affect the health of mothers and babies. The Korean government recognises OCUA could be a serious public health concern. To address the disparities, the Korean government designated OCUA and support operation budgets for obstetric care facilities or equipment. Furthermore, the Korean government would like to establish the OHAT for OCUA regions. Efficient resource allocation is crucial even in equity policies run by government and thus evidence is needed to guide these policies.

According to definition of OCUA by government (2014), suboptimal hospital access is defined as travel time of $60 \mathrm{~min}$ or more although no previous studies examined the evidence behind the $60 \mathrm{~min}$ benchmark in South Korea. In order to develop policies on prenatal care and delivery services for underserved areas, consensus on what constitutes suboptimal hospital access time (in opposition to OHAT) is urgently needed.

Several studies reported that the amount of resources available are associated with geographical accessibility to neonatal and maternal care. ${ }^{21}{ }^{22}$ A shortage of obstetricians in rural areas has led to an increase in the rate of pregnancy-related complications and mortality and found a $9 \%$ increase was associated with the loss of local specialist obstetrical care. ${ }^{23}$ Based on these results, the Korean government need to expand the installation of the perinatal centre and increase specialist obstetrical care in vulnerable areas and concentrated resources. Similar Japanese policies resulted in reduction of access time to hospital of about $28 \mathrm{~min}$ over the course of 4 years and resulted in the decrease of neonatal deaths. ${ }^{24}$ The median travel time reduced from $66.9 \mathrm{~min}$ in 2002 to $39.1 \mathrm{~min}$ in 2006 and the mean neonatal mortality rate decreased from 1.72 to 1.33 over the same period. In addition, study authors recommended reduction of time needed for interfacility transportation to under $60 \mathrm{~min}$ and an increase of the number of obstetricians per 10000 childbirths for country-wide reduction of adverse outcomes.

Following the establishment of OHAT, the Korean government should take initiatives to protect the health of pregnant women in OCUA in two ways. First, they should provide special services for pregnant women who have travel over $60 \mathrm{~min}$ to hospitals. Second, when planning new hospital for childbirth, a location where the highest number of prospective pregnant women could be served within the catchment area should be considered. The most significant strength of this study is that we used large linked database representing all pregnancies in South 
Table 4 OR for obstetric complications by travel time on multiple logistic regression analysis ${ }^{*}$

\begin{tabular}{|c|c|c|c|}
\hline Obstetric complications & Travel time & aOR $(95 \% \mathrm{Cl})$ & $P$ value \\
\hline Inadequate prenatal care & $\begin{array}{l}41-50 \mathrm{~min} \\
\text { (reference: } \leq 40 \mathrm{~min} \text { ) }\end{array}$ & 1.17 (1.06 to 1.28$)$ & 0.001 \\
\hline Placental abruption & $\begin{array}{l}51-60 \mathrm{~min} \\
\text { (reference: } \leq 50 \mathrm{~min} \text { ) }\end{array}$ & 3.23 (1.57 to 6.64$)$ & 0.0014 \\
\hline Postpartum transfusion & $\begin{array}{l}31-40 \mathrm{~min} \\
\text { (reference: } \leq 30 \mathrm{~min} \text { ) }\end{array}$ & 1.47 (1.22 to 1.67$)$ & $<0.0001$ \\
\hline Uterine artery embolisation & $\begin{array}{l}31-40 \mathrm{~min} \\
\text { (reference: } \leq 30 \mathrm{~min} \text { ) }\end{array}$ & 1.54 (1.05 to 1.83$)$ & 0.0093 \\
\hline
\end{tabular}

${ }^{*}$ Adjusted for age, socioeconomic status, Carlson Comorbidity Index, urbanisation and volume of the hospital. aOR, adjusted OR; ICU, intensive care unit.

Korea to investigate the association between geographical access time and adverse maternal outcome. The access time to hospital was calculated by using the road network analysis by GIS with big national health data, which lends further credibility to its results.

However, there are some limitations in this study. First, our study did not reflect the actual event location, that is, where contractions started; we used registered patient address rather than the location where labour started. Second, we adopted the Kessner Index ${ }^{15}$ to define inadequate prenatal care, and considered the care to be 'inadequate' when there were fewer than four prenatal care visits. Therefore, we were only able to evaluate the quantity of visits and not the quality of care received. Third, some essential health outcomes of neonates such as neonatal weight, congenital anomalies or infant mortality could not be examined due to restricted access to relevant data.

In sum, the OHAT for each obstetric complications ranges between 31 and $60 \mathrm{~min}$. Korean government should consider these OHATs when establishing health policies for pregnant women and should provide special interventions reducing areas of which access time to hospital exceed OHAT.

\footnotetext{
Author affiliations

${ }^{1}$ Center for Public Health, National Medical Center, Seoul, South Korea

${ }^{2}$ Department of Obstetrics and Gynecology, Seoul National University College of Medicine, Seoul, South Korea

${ }^{3}$ Department of Nursing Science, Shinsung University, Dangjin, South Korea

${ }^{4}$ Department of Preventive Medicine, Chungnam National University College of

Medicine, Daejeon, South Korea

${ }^{5}$ Health Review and Assessment Committee, Health Insurance Review \& Assessment Service, Wonju, South Korea

${ }^{6}$ Deaprtment of Health Policy and Management, Seoul National University College of Medicine, Seoul, South Korea
}

${ }^{7}$ Department of Public Health and Community Medicine, Seoul Metropolitan Government - Seoul National University Boramae Medical Center, Seoul, South Korea

Contributors Research conceptualisation and design: MYK, SML, SJE, YK, JYL. Data analysis and interpretation: MYK, HJ, and SJE. Statistical analysis: MYK. Drafting of the manuscript: MYK, SML, HJ and WMJ. Critical revision of the manuscript: YK, JYL, HJ, WMJ and HJK. Receiving grant: YK. Approval of final manuscript: all authors.

Funding This research was supported by National Health Insurance Service in South Korea (HIRE 15-39).

Map disclaimer The depiction of boundaries on the map(s) in this article do not imply the expression of any opinion whatsoever on the part of BMJ (or any member of its group) concerning the legal status of any country, territory, jurisdiction or area or of its authorities. The map(s) are provided without any warranty of any kind, either express or implied.

Competing interests None declared.

Patient consent for publication Not required.

Ethics approval The study was reviewed and approved by the Institutional Review Board (IRB) of Seoul National University College of Medicine (IRB No. E-1504-075$665)$. The need for informed consent was waived by the board.

Provenance and peer review Not commissioned; externally peer reviewed.

Data availability statement All data relevant to the study are included in the article.

Open access This is an open access article distributed in accordance with the Creative Commons Attribution Non Commercial (CC BY-NC 4.0) license, which permits others to distribute, remix, adapt, build upon this work non-commercially, and license their derivative works on different terms, provided the original work is properly cited, appropriate credit is given, any changes made indicated, and the use is non-commercial. See: http://creativecommons.org/licenses/by-nc/4.0/.

\section{REFERENCES}

1. Millman M. Access to health care in American. Washington, DC: National Academies Press, 1993

2. Grzybowski S, Stoll K, Kornelsen J. Distance matters: a population based study examining access to maternity services for rural women. BMC Health Serv Res 2011;11:147. 
3. Engjom HM, Morken N-H, Norheim OF, et al. Availability and access in modern obstetric care: a retrospective population-based study. BJOG 2014;121:290-9.

4. Ravelli ACJ, Jager KJ, de Groot MH, et al. Travel time from home to hospital and adverse perinatal outcomes in women at term in the Netherlands. BJOG 2011;118:457-65.

5. BJ N, Kim HJ, Lee JY. An early stage evaluation of the supporting program for obstetric care underserved areas in Korea. $J$ Korean Med Sci 2014;29:764-70.

6. Goertzen J. The four-legged kitchen stool. recruitment and retention of rural family physicians. Can Fam Physician 2005;51:84-6.

7. Brooks RG, Walsh M, Mardon RE, et al. The roles of nature and nurture in the recruitment and retention of primary care physicians in rural areas. Acad Med 2002;77:790-8.

8. Khalil A, Rodgers M, Baschat A, et al. ISUOG practice guidelines: role of ultrasound in twin pregnancy. Ultrasound Obstet Gynecol 2016;47:247-63.

9. Cheung YB, Yip P, Karlberg J. Mortality of twins and singletons by gestational age: a varying-coefficient approach. Am J Epidemiol 2000;152:1107-16.

10. Barrett JFR, Hannah ME, Hutton EK, et al. A randomized trial of planned cesarean or vaginal delivery for twin pregnancy. $N$ Engl $J$ Med 2013;369:1295-305.

11. Anthoulakis C, Dagklis T, Mamopoulos A, et al. Risks of miscarriage or preterm delivery in trichorionic and dichorionic triplet pregnancies with embryo reduction versus expectant management: a systematic review and meta-analysis. Hum Reprod 2017;32:1351-9.

12. Papageorghiou AT, Avgidou K, Bakoulas V, et al. Risks of miscarriage and early preterm birth in trichorionic triplet pregnancies with embryo reduction versus expectant management: new data and systematic review. Hum Reprod 2006;21:1912-7.

13. Kayıran SM, Erçin S, Kayıran P, et al. Relationship between thyroid hormone levels and transient tachypnea of the newborn in late- preterm, early-term, and term infants. $J$ Matern Fetal Neonatal Med 2019;32:1342-6.

14. Kessner DM. Infant death: an analysis by maternal risk and health care. Washington, DC: Institute of Medicine, 1973.

15. Lee JY, Jo M-W, Yoo W-S, et al. Evidence of a broken healthcare delivery system in Korea: unnecessary Hospital outpatient utilization among patients with a single chronic disease without complications. $J$ Korean Med Sci 2014;29:1590-6.

16. Sundararajan V, Quan $\mathrm{H}$, Halfon P, et al. Cross-National comparative performance of three versions of the ICD-10 Charlson index. Med Care 2007;45:1210-5.

17. Woo HK, Park JH, Kang HS, et al. Charlson comorbidity index as a predictor of long-term survival after surgery for breast cancer: a nationwide retrospective cohort study in South Korea. J Breast Cancer 2010;13:409-17.

18. Taylor WA. Change-Point analysis: a powerful new tool for detecting changes. Libertyville, IL: Baxter Healthcare Corporation, 2000.

19. Taylor WA. Change-Point analyzer 2.0 shareware program. Taylor Enterprises, 2000. Available: http://www. variation. com/cpa [Accessed 07 Apr 2019].

20. Smadi MM. Observed abrupt changes in minimum and maximum temperatures in Jordan in the 20th century. Am J Environ Sci 2006;2:114-20.

21. Mayer ML. Disparities in geographic access to pediatric subspecialty care. Matern Child Health J 2008;12:624-32.

22. Pilkington $\mathrm{H}$, Blondel $\mathrm{B}$, Carayol $\mathrm{M}$, et al. Impact of maternity unit closures on access to obstetrical care: the French experience between 1998 and 2003. Soc Sci Med 2008;67:1521-9.

23. Larimore WL, Davis A. Relation of infant mortality to the availability of maternity care in rural Florida. J Am Board Fam Pract 1995;80:392-9.

24. Aoshima $\mathrm{K}$, Kawaguchi $\mathrm{H}$, Kawahara K. Neonatal mortality rate reduction by improving geographic accessibility to perinatal care centers in Japan. J Med Dent Sci 2011;58:29-40. 